\title{
Research and application of online SPOC teaching mode in analog circuit course
}

Yuchen Jia* ${ }^{*}$ and Limei Zhang

*Correspondence:

jiayuchen1981@163.com

College of Information

Science and Technology,

Hebei Agricultural University,

Baoding 071001, Hebei,

China

\begin{abstract}
With the development of information technology and the advent of Massive Open Online Course (MOOC) and Small Private Online Course (SPOC), various online courses which include a lot of new resources and new teaching methods have appeared. The application of advanced teaching resources and educational concepts can improve students'learning experiences. This paper proposes a hybrid closed-loop teaching model of analog circuit SPOC based on online live. The course design is centered on the improvement of students' abilities. An online course resources construction mode of self-built platform with excellent courses introduction is expounded. It enriches the number of online course resources and increases the forms of resource expression. In teaching design, here present the target classification method based on Bloom, the indicators of the Bloom model corresponding to the knowledge, process arrangement, and tests of analog circuits. It also discusses the rules and presentation methods of learning goals, and online experiment teaching based on simulation. Taking the analog circuit course as an example, the implementation methods of resource construction, goal setting, live class schedule, PBL summary, course test, experimental teaching are described. Finally, it summarizes the methods of teaching data collection and the idea of optimizing teaching design applying feedback data. The current data shows that online SPOC teaching mode is conducive to improving students' interest in learning and cultivating their comprehensive ability.
\end{abstract}

Keywords: SPOC, Closed-loop instructional, Student centered, Curriculum resources, Bloom's classification, PBL

\section{Introduction}

The development of educational informatization has brought about great changes in educational forms and learning methods. It promotes the reform of education, having a great impact on traditional educational thoughts, concepts, models, contents and methods. MOOCs (Massive open online courses) are the products of "Internet + education". It is also a very good choice in practical teaching. Especially with the advent of the information age, new blood has been injected into the construction of the MOOCs platforms. Studying the operation mode of the platform can clarify the talent training mode and help the talent development (Pan and Zuo, 2018). MOOCs are open to the public by virtue of numerous high-quality resources, which emphasizes learners' complete autonomous learning. At present, in Chinese universities, engineering courses for author(s) and the source, provide a link to the Creative Commons licence, and indicate if changes were made. The images or other third party material in this article are included in the article's Creative Commons licence, unless indicated otherwise in a credit line to the material. If material is not included in the article's Creative Commons licence and your intended use is not permitted by statutory regulation or exceeds the permitted use, you will need to obtain permission directly from the copyright holder. To view a copy of this licence, visit http:// creativecommons.org/licenses/by/4.0/. 
students are generally taught in small classes with fixed time and place. Students need not only MOOCs resources for autonomous learning, but also teachers' guidance. So, SPOC is more practical for this kind of context. SPOC (Small Private Online Course) is a kind of online and offline hybrid teaching mode based on online resources in a small scope. The SPOC platform is divided into two parts, online courses and offline teaching activities. Therefore, the influencing factors of SPOC teaching are online resources and offline teaching activities (Freitas and Paredes, 2018). SPOC technology is also constantly updated and improved. Charlotte Vaysse (2018) proposed a new digital teaching technique based on SPOC. They divided the course into six topics. A final examination was offered in each session. They evaluated participants' satisfaction rate through a questionnaire and the success of the SPOC by participants' completion, success, and commitment rates. Based on data, curriculum optimization is carried out to achieve teaching objectives. Jiujiu $\mathrm{Yu}$ (2018) based on the analysis of the current application of SPOC platform, described the technical points of SPOC implementation.

SPOC is often used in conjunction with flipped classroom. In this teaching mode, students prepare before class, focus on active project-based learning in class, and work together to solve the challenges, so as to get a deeper understanding. Through the roles changes of students and teachers, the discussion can not only help to master knowledge, but also achieve emotional communication. Research shows that the flipped classroom may benefit lower performing student's knowledge acquisition and transfer to a greater degree than higher performing students (Day 2018). Erwen Zhang proposed that the SPOC-based flipped classroom of college English can serve as an effective learning model in teaching and learning practice which has promoted English learning by providing rich resources, environment, flexible time and space (Zhang et al., 2018). Cognitive style and learning strategy significantly affected students' learning performance and satisfaction in both the flipped and revised flipped classrooms (Yuh-Tyng et al. 2019). To carry out flipped classroom teaching, it is necessary to provide a lot of learning resources and design classroom activities. Currently, the flipped classroom is mainly performed offline.

With the development of the Internet, various online course platforms provide a friendly environment for online course construction. In addition to providing resources used by students, the statistics of online courses provide a useful tool for teaching feedback. Quality feedback is crucial to learning, while the growth of online delivery has altered how it is obtained and shared (Meikleham and Hugo, 2018). Only by grasping the feedback data can the course resources and instructional design be adjusted more effectively. Through online learning and discussion, students continue to accumulate skills for seeking feedback (Bing-You et al., 2018). Feedback mechanism is very important in teaching research. Students' feedback literacy has an impact on the operation of feedback mechanism. Three key mechanisms of inspiration, processing and implementation are embedded in teaching practice to cultivate students' feedback literacy (Malecka et al., 2020). With the help of online course statistics, the learning process becomes a closed-loop. It provides a guarantee for efficient teaching and learning.

Usually, SPOC, as a teaching mode combining students' autonomous learning with teachers' guidance, is conducted using online resources and offline flipped classrooms. Previously publishing studies show that SPOC is generally associated with flipped 
classroom, which requires high quality and quantity of resources and pays attention to feedback data. The form and quantity of online resources have a great influence on students' autonomous learning. Teachers need to adjust teaching resources and progress according to the feedback data of students' tests, discussions and assignments, so as to guide students' learning. Therefore, it is of great significance to study SPOC resource construction mode and offline teaching methods. This paper elaborates on the studentcentered online SPOC teaching model and explores the advantages of this model.

\section{Student centered SPOC instructional design}

The focus of teaching is students, so teaching design should be student-centered. For students, the purpose of learning is to acquire knowledge and transform it into the promotion of essential skill like practical ability, working ability, learning ability, etc. The analog circuit course is a professional basic course connecting the previous course and follows, both theoretical and engineering. Its knowledge points are various and highly related. In addition to strong theoretical, it is very close to engineering practice. It is a course to cultivate students' practical ability. Its macro concept, circuit analysis and design methods are universal in a hardware course. So, it teaches not only knowledge, but also the ability to learn knowledge. Therefore, the teaching concept should be "taking students' learning ability improvement as the center ".

All the construction of resources and design of teaching links are to let students understand "what to learn", "how to learn" and "what has been learned". In the studentcentered education, students' knowledge structure, ability needs, cognitive rules and learning habits are the core of teaching research. When teachers construct teaching resources and design teaching process, they should take the core of teaching research as the basis (Doghonadze and Kerdikoshvili, 2018; Jay, 2018). The online learning environment should also be student-centered (Santoso et al., 2018; Kandi and Basireddy, 2018). In the concept of technical learning, we should pay attention to students' cognitive input, stimulate students' internal learning motivation, pay attention to the systematic construction of knowledge, and promote the effective achievement of high-level thinking goals (Cao and Zhu, 2019). In addition to learning knowledge, students should also master methods and cultivate their ability in the learning process. Therefore, this paper proposes a hybrid closed-loop teaching design scheme to improve students' ability. It focuses on the construction of curriculum resources, teaching design methods and experimental teaching reform.

\section{Hybrid closed-loop teaching design}

There is no face-to-face communication between teachers and students in online learning and live tutoring. To improve students' learning efficiency, we need to enrich the online resources and perfect teaching design methods. Through the preparation, practice, stage test and other links, here give a set of hybrid closed-loop teaching design method. The scheme block diagram is shown in Fig. 1.

The hybrid closed-loop teaching design method relies on abundant online resources and interactive modules, as well as the opportunity to communicate with teachers in live class to guide students' autonomous learning. The design of each link in the diagram is aimed at improving students' learning ability. It is of great significance when cultivating 


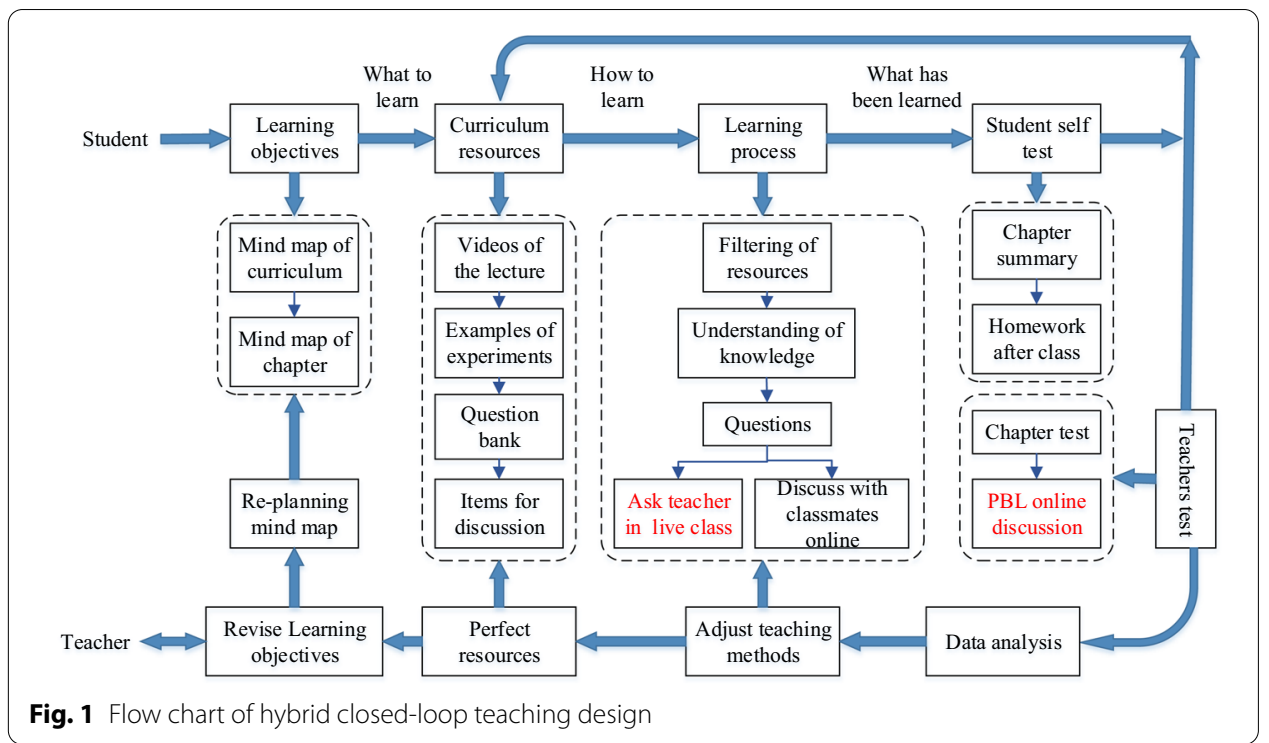

students' lifelong learning ability. Due to the construction of course platform and convenient network interaction, it is very easy to online course resources, guide students to self-study and collect students' feedback data. Therefore, this design method can be easily integrated into SPOC online learning and live communication, such as targeted video watching and thematic live broadcasts. This method is very suitable for analog circuit course, which has many knowledge points and are difficult to understand. The students need to study them repeatedly to find the relationship, and then better establish the knowledge system and cultivate their reasoning ability. In this way, students form a small circle in the learning process. According to the feedback data, teachers adjust the teaching methods, supplement the resources and revise the objectives, and feed back to the students' learning links synchronously, thus forming a large teaching cycle. Consequently, it can form a teaching method that students study separately and teachers focus on solving problems.

\section{Curriculum resources construction}

SPOC is based on online resources. The carrier of resources is online courses. Therefore, first of all, it needs to establish an online course to store and display resources. Analog circuit is an online course built on the Chaoxing platform (https://www.xueyinonli ne.com/detail/216509393), which has both web and mobile app. This platform has the template of course resource storage, question bank, homework, examination and selftest, which is convenient to establish courses. And it has the functions of resource storage, teacher-student interaction, student management, data statistics, etc. It is not only a simple list of resources, but also the management of resources, students, activities and data. Here call it a self-built course, which is a management platform for students' learning data related to study, discussion, test and homework. It is a window for teachers to understand students' online learning.

In addition, some excellent courses about analog circuit from external schools are introduced to extend the curriculum resources. In the era of high dependence on 
Internet, online resources are often their first choice when students decide what to learn. The resources of self-built courses may not meet the needs of students in quantity and form, but the idea of using excellent curriculum resources for teaching, which is recognized by Chinese education departments, can make up for the defects in application. Therefore, for analog circuit courses, three national and provincial excellent courses are added, and the number of videos has expanded from 62 to 320. Excellent MOOC resources provide students with diverse learning programs (Sneddon et al., 2018). Only when there are enough resources, students can choose and find out what fits their cognition. Only when the cognitive focus of students fit the teaching focus, can we achieve the unity of teaching and learning, and students can learn with half the effort. That is also conducive to the cultivation of their knowledge screening ability, that is, the ability to learn.

Finally, the purpose of resource construction is application. Only when curriculum resources are used can their value be realized. Therefore, the manifestation of resources is also very important. The resources in the self-built courses include videos, PPT, problem solving, special lectures and chapter tests. The videos are recorded by teachers themselves. The main resources are lecture videos in supplementary courses.

\section{Teaching design method based on target classification}

Teaching design based on excellent resources is another focus of online SPOC. The first step is to determine an attainable goal and design a feasible idea according to the situation of students. The ISCED (International Standard Classification of Education Design) classification used in education is the most important step in designing and constructing forecasts and prevision models (Silvestru et al., 2018). For the goal setting, we use Bloom's education goal classification for reference. This method divides educational goals into three domains: cognitive domain, affective domain and psychomotor domain. The cognitive domain includes the understanding and memory of knowledge, the interpretation and inference of things, the correct application of knowledge, the analysis of internal relations of knowledge, and the evaluation of the essence of things. The affective domain is divided into five levels: acceptance, reflection, formation of values, organization of value system and personalization of value system. Bloom was only aware of the existence of the psychomotor domain when he set up the education goal, and did not set out the specific goal level. With the in-depth study of this theory, people have developed seven levels including perception, stereotype, guided reflection, mechanical action, complex explicit reflection, adaptation and innovation. This classification method is applied to the examination, according to the cognitive field to establish a test classification model, and according to the students' cognitive level to send different papers (Mohammed and Omar, 2020). In the application of bloom classification, this method is improved according to the actual situation. According to the different cognitive level of students, the test of different knowledge level is established to test the ability of students, and the results are more objective (Ramlawati et al., 1567).

The design of analog circuit course is carried out according to Bloom's education goal classification, and it's not just for exams. The analog circuit course prepares knowledge points and questions according to students' different cognitive levels and classification in learning process and examination. It is shown in Fig. 2. 


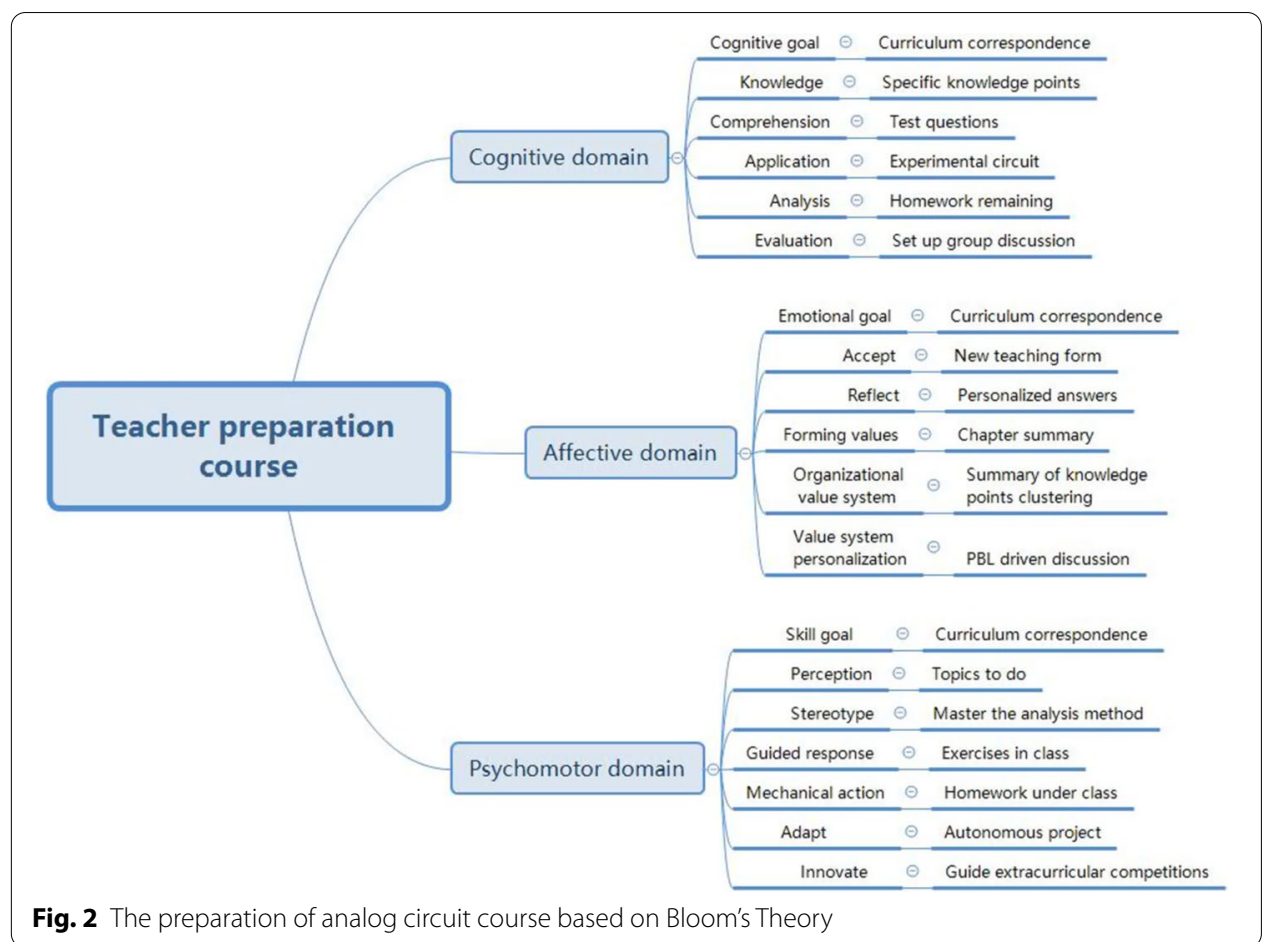

Determination of an attainable goal is the beginning of this process. In the face of more than 600 pages of textbooks, what method can let students understand its content as quickly as possible? Drawing mind maps is advocated a good way. Due to simple and clear, it is easy to stimulate students' desire to explore knowledge. For clarity of learning objectives and knowledge points, mind map for every chapter of analog circuit course is drawn. Then, teachers guide students to understand the connection of knowledge points, so as to better preview. The task following setting the goal is how to achieve the goal. According to Bloom's classification of educational objectives, teaching design is carried out, as shown in Fig. 3.

From Fig. 3, knowledge construction and learning goals are divided into six progressive levels. In teaching, the six levels correspond to before class, in class and after class. Teachers guide students to use different learning methods in each stage according to students' cognitive level and planning goals.

\section{Experimental teaching based on software simulation}

As an engineering course, analog circuit requires to set up the corresponding experiment, which is an important and essential composition to arrive at course requirements. Usually, the experiment of analog circuit is arranged in the laboratory to build and test the circuit. Due to the limitation of hardware resources, most of the traditional experiments are lack of innovation and flexibility. Software simulation has a long history. The introduction of simulation into teaching is conducive to the extension of practice. There are also many achievements in these aspects. Some studies have integrated OBE (Outcomes-based Education) education concept into the teaching of mechanical virtual and practical combination. Using IRAI software platform 


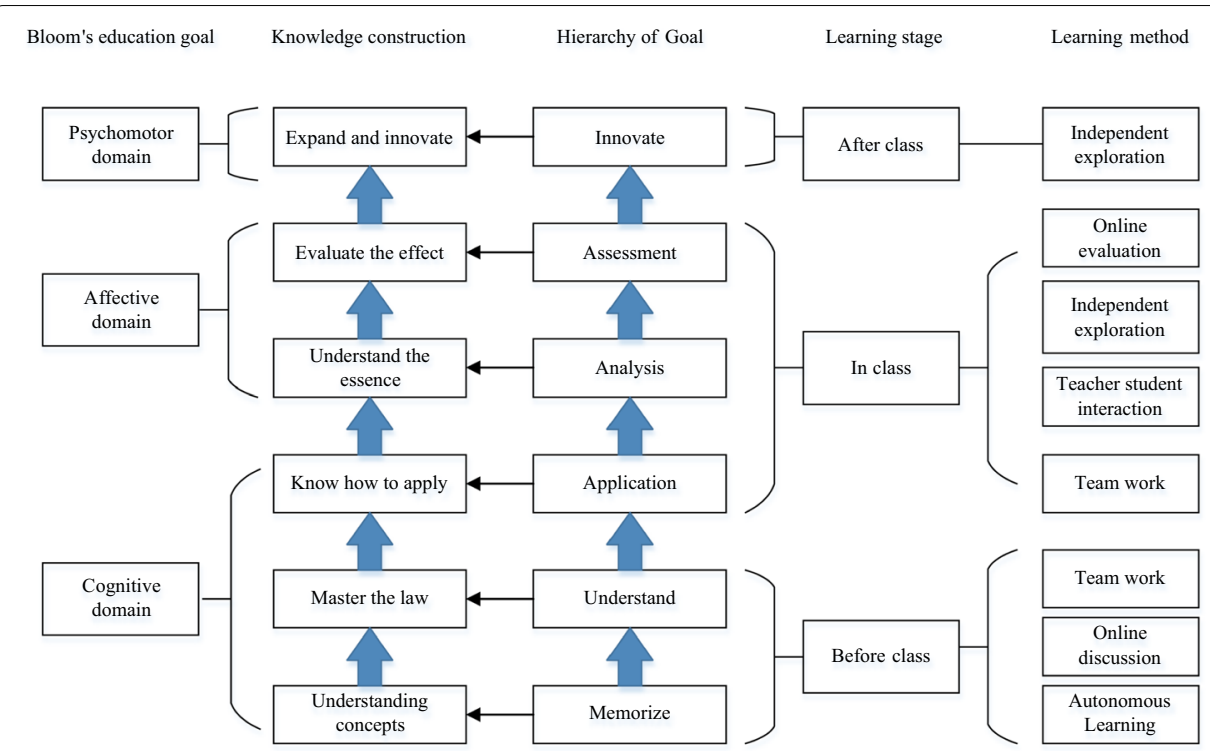

Fig. 3 Teaching design based on Bloom's education goal classification

to develop training projects, that is, using real PLC (Programmable Logic Controller) and other electrical control components to control the virtual mechanism movement in PC (Zhao et al. 2018). Our reform of experimental teaching began in 2016. In 2016, Muitisim simulation was introduced as an auxiliary tool. In 2017, the Muitisim simulation experiment was included in the experiment results as a bonus item. In 2018, the innovative experiments that cannot be realized on the experimental box were transferred to the simulation software, and the proportion of simulation experiment scores was increased. In 2019, continue to increase the fraction proportion of simulation experiments. The number of simulation experiments is gradually increased, especially comprehensive and innovative experiments.

Since 2020, simulation experiment courses have been arranged. With the use of SPOC, the experimental mode is changed to simulation + field practice + summary. The typical characteristic of simulation experiment is that it is not limited by time and space. Students can do a certain experiment repeatedly and change the circuit structure at will.

In order to improve students' learning ability, a hybrid closed-loop teaching mode is established based on online resources. Based on Bloom's education goal classification, the teaching process and method are designed. With the help of software simulation tools, the cultivation of students' practical innovation ability is strengthened. These methods are suitable for analog circuit course.

\section{SPOC teaching model of analog circuit under}

Under the guidance of the correct concept, relying on rich teaching resources, according to the various methods described above, we carry out the teaching practice of analog circuit course. Teaching activities are divided into four stages, which are pre class preview, live class communication between teachers and students, phased PBL summary, data feedback and analysis. 


\section{Pre class learning using online resources}

Before offline class, students receive a task list about the chapters that will study, and they should finish them within the prescribed time. To complete the tasks in the list, students must self-study using online resources. There are two forms of resources application, one is students' spontaneous watching video, doing homework, initiating class discussion. And the other is that teachers issue examinations to students, and students should study to complete the examination questions. The former is called active test. Students can learn spontaneously, give full play to their subjective initiative, and test the effectiveness of their own learning. This group of students can generally reach the fifth or sixth hierarchy of the goal shown in Fig. 3. The latter is called passive test. Students' subjective initiative is relatively poor, so teachers' supervision is needed to complete the tasks. Students cannot do self-examination, but are tested the effectiveness by teachers. This group of students can generally reach the third or fourth hierarchy of the goal shown in Fig. 3. Both methods need to use online resources to test the achievement of the goal. According to the theory of feedback correction reinforcement, students can re-plan the learning progress according to the feedback information, and teachers can adjust the form and quantity of resources. The curriculum resources of analog circuit are adjusted dynamically. With the further development of SPOC, the use of resources is also adjusting. Table 1 shows the number of new resources to be added in 2020 and the comparison of resource use in 2020 with the previous year's draw level. The data in Table 1 is an important basis for future resource adjustment.

\section{Arrangement of live courses}

SPOC focuses on online and offline mixing. The application of course resources is online, and the live class is offline. In live class, the teacher answers questions by interacting with the students, testing the students' goal achievement and helping the students learn better. The task of live class is application, analysis and evaluation of knowledge. The method of negotiation between students and teachers is adopted for the selection of the time of live class, which is $90 \mathrm{~min}$. The schedule is shown as follow.

(1) 15 min: see mind map, talking about knowledge points, inspection target achievement.

(2) 30 min: students ask questions, teacher answer.

Table 1 Application statistics of analog circuit online resources

\begin{tabular}{|c|c|c|c|c|}
\hline & $\begin{array}{l}\text { Quantity of resources } \\
\text { before } 2020\end{array}$ & $\begin{array}{l}\text { Additional } \\
\text { resources in } 2020\end{array}$ & $\begin{array}{l}\text { Average usage } \\
\text { before } 2020\end{array}$ & Usage in 2020 \\
\hline Videos & 62 & 320 & $42 \%$ & $76 \%$ \\
\hline Item bank & 585 & 327 & 3 times/item & 4 times/item \\
\hline Test & 35 groups & 22 groups & 2 times/groups & 28 groups \\
\hline Homework & 31 groups & 9 groups & 2 times/groups & 18 groups \\
\hline Responder & 50 times & 7 times & 2 times & 16 times \\
\hline Discuss & 20 times & 5 times & 3 times & 9 times \\
\hline Select answer & 32 times & 12 times & 4 times & 24 times \\
\hline Group tasks & 21 times & 13 times & 2 times & 18 times \\
\hline Questionnaire & 18 groups & 11 groups & 2 times/groups & 16 groups \\
\hline
\end{tabular}


(3) 15 min: quiz test, test the ability to use knowledge.

(4) 20 min: teacher explanation, student explanation, knowledge enhancement.

(5) 10 min: see mind map, assign new tasks.

\section{Phase summary based on PBL}

Analog circuit emphasizes the comprehensive use of knowledge. In order to improve students' comprehensive ability, PBL training is carried out by combining online and offline learning. We use the PBL of Chaoxing platform and Tencent conference live report to make a phased summary. Tencent conference is an online interactive software, which can provide one-stop cloud conference solutions. Also, it can provide desktop sharing, online documents, voice and video transmission and other functions. It runs on Windows system and Android system, and needs little data flow. It has been proved that tencent conference is a very good tool for course live broadcast.

PBL (Problem-Based Learning) is a kind of learning method that takes students as the focus, various problems in the professional field as the starting point. It takes problems as the core to plan the learning content and let students seek solutions around problems. The role of teachers in this process is to ask questions, design courses and evaluate results. The purpose is to improve students' subjective initiative through guidance and reward. Different from traditional teaching, the focus of PBL is not for teachers, but for students. The general steps of PBL are: teachers put forward problems, analyze problems, solve problems, and evaluate results. In the process of implementation, tracking can be added. Song Zhang (2018) applied the PBL teaching method to Chinese radiology education. Yunfeng He (2017) proposed the effectiveness of PBL teaching methods in medical education. PBL teaching methods are widely used in medical education.

Here is an example of PBL. For the first two chapters of analog circuit, we designed six projects. 30 students in each class were divided into 6 groups, with 12 groups in two classes. For comparison, each class has a team to complete the same project, that is, the same topic corresponds to two groups. A team leader was appointed for each project, and he selected his own team members for discussion online within $48 \mathrm{~h}$. This is the online learning process of SPOC. Students are the focus and they choose their own learning resources. The course platform has the function of collecting data, and teachers collect data from the background. Table 2 shows the students' posts and resources uploaded within $48 \mathrm{~h}$.

After $48 \mathrm{~h}$ of online discussion, each group forms a report. Next, the leader of each group will use Tencent meeting to report the project results to all students. In the process of the speech, other groups can ask questions, and finally the teacher makes comments. After class, the teacher gives the evaluation score through the course platform, accounting for $60 \%$ of the total score. For other parts, self-evaluation was $20 \%$, intra group evaluation was $10 \%$, and inter group evaluation was $10 \%$. At the end of the phase PBL, the overall evaluation results are displayed on the course platform. For example, 99.6 (a student's score) $=100$ (teacher evaluation) $* 60 \%+100$ (intra group evaluation) $* 10 \%+95.7$ (inter group evaluation) *10\%+100 (self-evaluation) * $20 \%$. In the evaluation, in order to ensure the objectivity of the evaluation, teacher evaluation is the highest. However, PBL achievements are not the focus. The key point is that through this 
Table 2 Number of views and posts during discussion

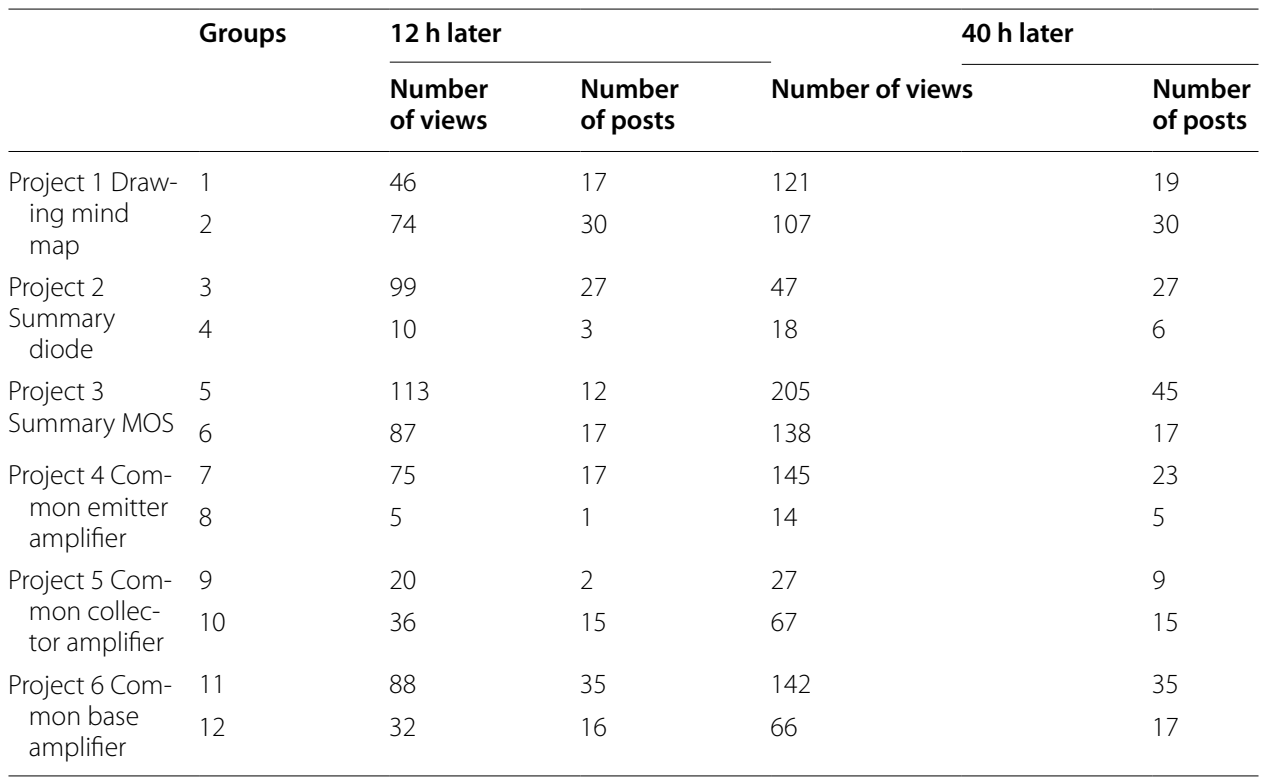

Table 3 Test results under different teaching modes

\begin{tabular}{llllllll}
\hline Score & $\mathbf{2 9 0}$ & $\mathbf{2} \mathbf{8 0}$ & $\mathbf{2 7 0}$ & $\mathbf{2 6 0}$ & $\mathbf{6 0}$ & Highest & Minimum \\
\hline 1 & 11 & 21 & 8 & 6 & 4 & 96 & 47 \\
2 & 6 & 25 & 16 & 9 & 18 & 94 & 40 \\
3 & 1 & 11 & 18 & 16 & 9 & 98 & 40 \\
\hline
\end{tabular}

kind of communication, students can grasp knowledge more naturally and enhance their cooperation ability.

\section{Acquirement of feedback data from test and homework}

No matter students or teachers, only by obtaining objective feedback data can they reasonably adjust the learning and teaching programs. Testing is a good way. It is helpful for students to understand their mastery of knowledge and find out the missing. At the same time, teachers can adjust course resources and teaching methods according to the data of the test results. Similarly, it is also necessary in live SPOC, but just the form of testing has to be changed. The test module provided by Chaoxing platform is used for phased test. It includes multiple-choice questions, fill in the blanks, judgment questions, short answer questions, calculation questions and other types of questions, which are very convenient to combine. Table 3 shows the test results of knowledge points in the first two chapters of analog circuit. The data in line 1 is the test results in April 2020, based on the online SPOC teaching mode. The data in line 2 is the test results in April 2019, based on the online and offline hybrid teaching mode. The data in line 3 is the test results in April 2019, based on the pure offline teaching mode.

In order to show the effect of the three different teaching modes more clearly, the curve chart of phased test data is drawn, as shown in Fig. 4. 


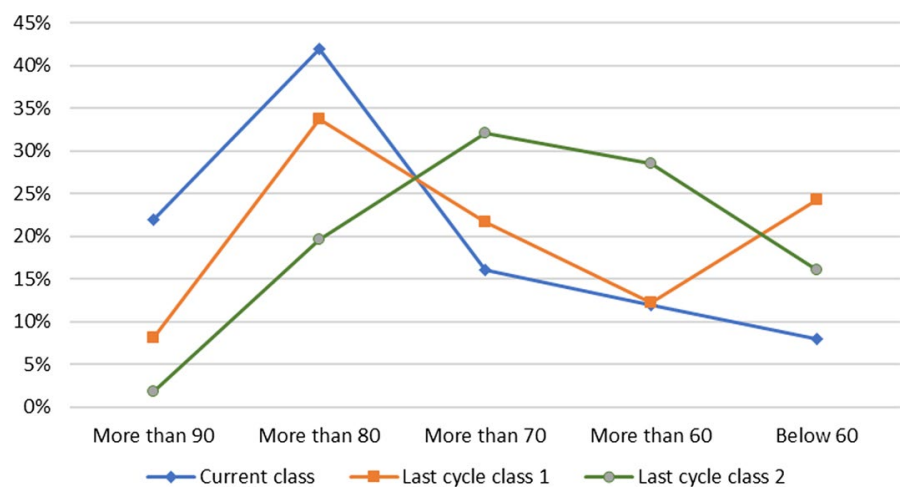

Fig. 4 Effect stage data curve of three different teaching modes

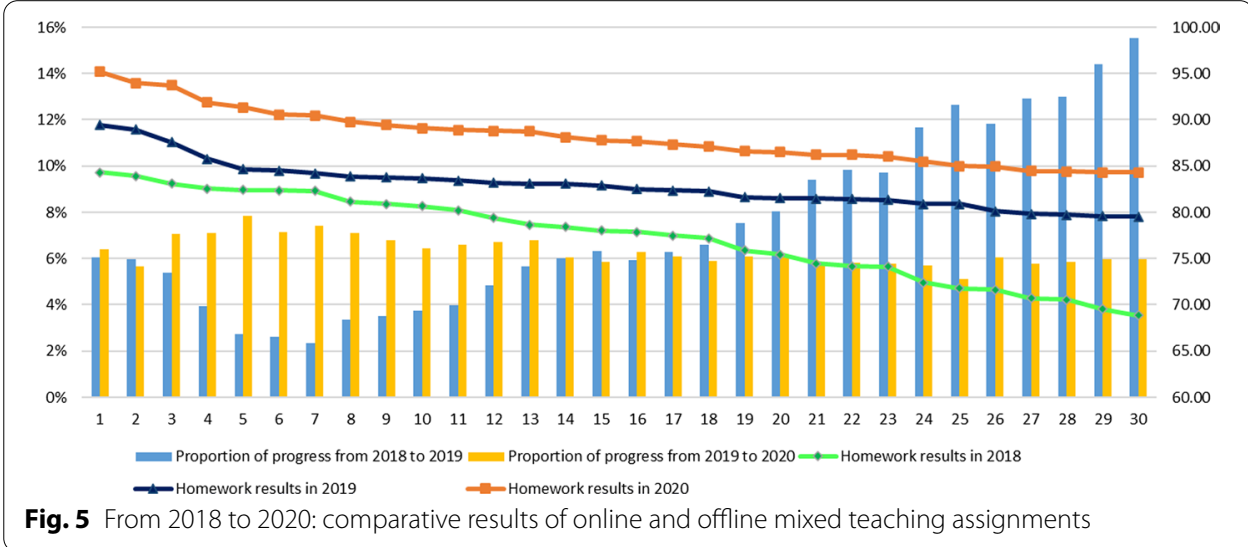

It can be seen from the above figure that the lowest score in current class is higher than the other two, and the proportion of people with a score below 60 is the lowest. From the curve, it can be seen that the proportion of more than 80 score is more than $60 \%$ in 2020, far higher than 2019. In addition to seeing the results, the course platform can also summarize the accuracy of each question, and help students and teachers to analyze which knowledge points are not firmly grasped.

Learning analog circuit needs to do a lot of circuit analysis and calculation, so doing homework is an essential part of learning. Through the feedback data of students' homework, we can also see the situation of knowledge mastery, so as to reflect the advantages and disadvantages of the teaching mode. We have compared the homework situation under different teaching modes, as shown in Fig. 5.

In 2020, we use online SPOC to teaching, and online and offline mixed teaching mode in 2019, and offline teaching mode in 2018. Through the comparison of homework scores, it can be seen from Fig. 5 that the addition of online courses improves homework scores. According to the ranking of grades from high to low, the part with obvious performance improvement is concentrated in the part with high homework score in 2020. It shows that online SPOC makes good students to love learning more. 


\section{Application of hybrid SPOC in experiment}

Experiment is an indispensable part of analog circuit course. It is the engineering application of theoretical knowledge. Under the background of innovative education, experiments play a greater role. In online SPOC mode, the experimental class is different from the theory class, and resources should be more abundant than the theory class, and the time in class can be shortened. The experimental class is arranged as follows.

(1) Record experimental course resources

There are few experimental resources of analog circuit based on Multisim. We need to record video of experimental requirements and steps, which include circuit symbol description, circuit connection method, circuit parameter index test method, etc. Multisim simulation-based experimental micro-lessons are put on the course platform.

(2) Pre class preparation

In fact, there is no time limit for the experimental class. Students follow the video to complete the basic experiment, and master the basic experimental process. For the problems encountered in the experiment, they can discuss in groups or ask teacher in class.

(3) In class

The experimental in class time can be very short, only a few minutes, and teachers open the live broadcast to answer students' questions.

(4) After class

The purpose of students' experiment is the comprehensive application and innovation of knowledge. After mastering the basic experimental methods, they can do complex and novel experiments. Students can give full play to their creativity and design experimental circuits by themselves.

(5) Experimental examination

The project-based test method was used in the experimental examination. Teachers set up experimental projects and give evaluation according to students' performance.

From April to June in 2020, students carried out online SPOC analog circuit experiments. They completed 7 basic and 5 comprehensive experiments, and 20 students completed 25 innovative projects.

\section{Conclusion}

Under the background of education informatization, this paper discusses the online and offline hybrid teaching methods. Through using the convenience of the network, an online SPOC teaching mode, which puts students' decentralized self-study and teachers' centralized teaching on the network, has been developed. This method is summarized as follows.

1) The ultimate goal of learning and teaching is to improve students' ability. To achieve this goal, a hybrid closed-loop teaching mode is established. The mode includes highquality resources, reasonable teaching methods, rich feedback data, and dynamic 
adjustment strategy. Through practice, this mode is beneficial to improve students' self-study ability, and it also brings convenience for teachers to analyze and adjust teaching methods.

2) Online resources are the foundation of hybrid closed-loop teaching mode. Besides recording videos and making courseware by teachers themselves, the other way is to lead into other excellent online courses to meet the needs of student resource selection. Three excellent courses are introduced in the analog circuit course.

3) Teaching methods are the key of hybrid closed-loop teaching mode. Bloom's education goal classification in analog circuit courses is studied. Corresponding to the cognitive domain, affective domain and psychomotor domain of the Blume classification model, the requirements of each chapter of the analog circuit course are designed.

4) Each course is a whole, and it is an important link to use the periodic summary to run through the knowledge points in the learning process. PBL is a good tool for teaching summary. Students work in groups to complete a project. After group discussion, report writing and class defense, PBL activities cultivate students' ability of summary, expression and cooperation.

5) The analog circuit experiment teaching mode based on simulation is proposed. Students use simulation software to build circuits and measure and analyze characteristics, and they can do more experiments. And it can also expand comprehensive and innovative experiments. Through this mode, active students have done 15 circuit experiments in 2020. This model lays a good foundation for students to participate in practical competitions.

The research results show that the live broadcast SPOC mode is suitable for analog circuit learning and teaching, and the test and homework results are better than the previous online and offline mixed teaching. With the continuous improvement of network speed, online teaching will develop faster. More courses will join the online SPOC in the future. This teaching mode is bound to be applied in digital circuit, signal and system, digital signal processing and other courses, and play a greater role.

Acknowledgements

This work was supported in part by Hebei Excellent Online Open Course "Analog Circuit" and supported by Hebei Higher Education Teaching Reform Research and Practice Project (2019GJJG104). This work was supported by China Ministry of education project "Research on Innovation and Entrepreneurship Education Model of Internet of Things Engineering (201902061040)" and "Internet of things artificial intelligence (201902306008)".

\section{Authors' Contributions}

YJ carried on the research of resource construction method and teaching mode design of online SPOC closed-loop network teaching. LZ collected and analyzed the data in the teaching process, and studied the experimental teaching mode. All authors read and approved the final manuscript.

\section{Funding}

There is no funding for this article.

Availability of data and materials

All data generated or analysed during this study are included in the article.

Ethics approval and consent to participate

Not applicable.

\section{Competing interests}

We declare that we have no financial and personal relationships with other people or organizations that can inappropriately influence our work, there is no professional or other personal interest of any nature or kind in any product, service and/or company that could be construed as influencing the position presented in, or the review of, the manuscript entitled. 
Received: 9 November 2020 Accepted: 15 February 2021

Published online: 27 February 2021

\section{References}

Barma, S., Romero, M., \& Deslandes, R. (2016). Implementing maker spaces to promote cross-generational sharing and learning. Game-Based Learning Across the Lifespan, 10, 65-78.

Bing-You, R., Hayes, V., \& Palka, T. (2018). The art (and artifice) of seeking feedback: Clerkship students' approaches in asking for feedback. Academic Medicine. https://doi.org/10.1097/ACM.0000000000002256.

Cao, M., \& Zhu, X. (2019). An interpretation of constructivism paradigm of online course design-case study of BrainPOP Online Course in America. Audio-Visual Education Research, 12, 57-63.

Day, L. J. (2018). A gross anatomy flipped classroom effects performance, retention, and higher-level thinking in lower performing students: Flipped anatomy effects lower performing students. A flipped classroom is a growing pedagogy in higher education. Anatomical Sciences Education., 11, 565-574. https://doi.org/10.1002/ase.1772.

Doghonadze, N., \& Kerdikoshvili, N. (2018) Planning in education and student-centered teaching. International Conference of Education, Research and Innovation, 3, 2018

Freitas, A., \& Paredes, J. (2018). Understanding the faculty perspectives influencing their innovative practices in MOOCs/ SPOCs: A case study. International Journal of Educational Technology in Higher. https://doi.org/10.1186/s4123 9-017-0086-6.

Garcia, A. L., Farran, J. A. P., \& Berbegal-Mirabent, J. (2019). ICT skills gap in Spain: Before and after a decade of harmonizing the European Higher Education Area. Computer Applications in Engineering Education, 27, 934-942.

Goldberg, J. R., \& Ranz, D. (2018). A student-centered learning approach to design for manufacturability: Meeting the needs of an often-forgotten customer. The International Journal of Engineering Education, 34, 599-608.

He, Y., Xiangyun, D., Toft, E., Zhang, X., Bo, Q., Shi, J., et al. (2017). A comparison between the effectiveness of PBL and LBL on improving problem-solving abilities of medical students using questioning. Innovations in Education and Teaching International., 10, 44-54. https://doi.org/10.1080/14703297.2017.1290539.

Jiang, H., Sun, Q., \& Zhao, Y. (2017). Inquiry into teaching mode combined with engineering case under background of engineering education accreditation. Heilongjiang Researches on Higher Education, 3, 162-164.

Jiujiu, Y. (2018). Research on key development technologies for SPOC platform. MATEC Web of Conferences. https://doi. org/10.1051/matecconf/201823201025.

Kandi, V., \& Basireddy, P. R. (2018). Creating a student-centered learning environment: Implementation of problem-based learning to teach microbiology to undergraduate medical students. Cureus. https://doi.org/10.7759/cureus.2029.

Liu, F., \& Wang, B. (2018). Teaching and research of cryptography for the new engineering course cyberspace security. Journal of Higher Education, 12, 1-4.

Malecka, B., Boud, D., \& Carless, D. (2020). Eliciting, processing and enacting feedback: mechanisms for embedding student feedback literacy within the curriculum. Teaching in Higher Education. https://doi.org/10.1080/13562 517.2020.1754784.

Meikleham, A., \& Hugo, R. (2018). Understanding feedback to improve online course design. European Journal of Engineering Education. https://doi.org/10.1080/03043797.2018.1563051.

Mohammed, M., \& Omar, N. (2020). Question classification based on Bloom's taxonomy cognitive domain using modified TF-IDF and word2vec. Library of Science, 15(3), 1-21. https://doi.org/10.1371/journal.pone.0230442.

Pan, L., \& Zuo, Na. (2018). Research on MOOCs platform construction and talent training model in information age. Information Science, 8, 21-24.

Ramlawati, Anwar, M., Yunus, S. R.. \& Nuswowati, M. (2019). Analysis of students' competence in chemistry cognitive test construction based on revised bloom's taxonomy. Journal of Physics: Conference Series, 2019. DOI: https://doi. org/10.1088/1742-6596/1567/042006

Santoso, H. B., Batuparan, A. K., Isal, Y. K., \& Goodridge, W. (2018). The development of learning dashboard for lecturers: Case study student centered e-learning environment. Journal of Educators. https://doi.org/10.9743/JEO.2018.1.1.

Shoemaker, D., Woody, C., \& Mead, N. R. (2016). Advances in software engineering and software assurance. Advances in computers (pp. 1-46). Amsterdam: Elsevier.

Silvestru, C. I., Ion, V., Botez, C., \& Cristina, I. (2018). ISCED classification influence on e-learning education systems. Informatica Economică. https://doi.org/10.12948/issn14531305/22.4.2018.07.

Sneddon, J., Barlow, G., Bradley, S., Brink, A., Chandy, S. J., \& Nathwani, D. (2018). Development and impact of a massive open online course (MOOC) for antimicrobial stewardship. Journal of Antimicrobial Chemotherapy, 73, 1091-1097. https://doi.org/10.1093/jac/dkx493.

Vaysse, C., Chantalat, E., \& Beyne-Rauzy, O. (2018). The impact of a small private online course as a new approach to teaching oncology: Development and evaluation. JMIR Medical Education. https://doi.org/10.2196/mededu.9185.

Yuh-Tyng, C., Shyhnan, L., \& Lin-Fan, C. (2019). The relationships among gender, cognitive styles, learning strategies, and learning performance in the flipped classroom. International Journal of Human-Computer Interaction, 35, 395-403.

Zhang, E., Zhang, W., \& Jin, C. (2018). SPOC-based flipped classroom of College English: Construction of an effective learning model. International Journal of Emerging Technologies in Learning. https://doi.org/10.3991/ijet.v13i01.7513.

Zhang, S., Jiancheng, Xu., Wang, H., Zhang, D., Zhang, Q., \& Zou, L. (2018). Effects of problem-based learning in Chinese radiology education: A systematic review and meta-analysis. Medicine (Baltimore)., 97, e0069. https://doi. org/10.1097/MD.0000000000010069.

Zhao, W., Liu, M., Liu, X., \& Han, L. (2018). Practice of practical training teaching system based on the concept of OBE. Experimental Technology and Management, 3, 185-189.

\section{Publisher's Note}

Springer Nature remains neutral with regard to jurisdictional claims in published maps and institutional affiliations. 